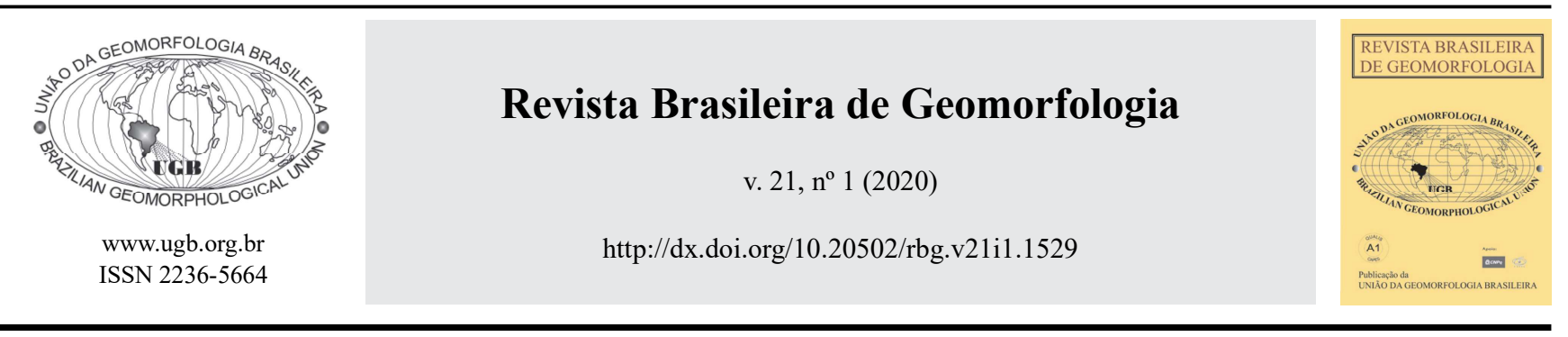

\title{
CENÁRIOS EVOLUTIVOS DA CONECTIVIDADE DA PAISAGEM EM AMBIENTE SEMIÁRIDO - BACIA DO RIACHO DO SACO, SERRA TALHADA, PERNAMBUCO
}

\author{
EVOLUTION SCENARIOS OF LANDSCAPE CONNECTIVITY IN \\ SEMIARID ENVIRONMENT - SACO CREEK WATERSHED, SERRA \\ TALHADA/PE - BRAZIL
}

\author{
Jonas Otaviano Praça de Souza \\ Departamento de Geociências, Universidade Federal da Paraíba \\ Cidade Universitária, João Pessoa, Paraíba CEP: 58051-900. Brasil \\ ORCID: 0000-0002-1405-0944 \\ E-mail: jonasgeoufpe@yahoo.com.br
}

\begin{abstract}
Antônio Carlos de Barros Corrêa
Departamento de Ciências Geográficas, Universidade Federal de Pernambuco Av. Acadêmico Hélio Ramos, s/n, Recife, Pernambuco. CEP: 50.740-530. Brasil
\end{abstract}

ORCID: 0000-0001-9578-7501

E-mail:dbiase2001@terra.com.br

\begin{tabular}{l} 
Informações sobre o Artigo \\
\hline Recebido (Received): \\
06/06/2019 \\
Aceito (Accepted): \\
12/10/2019
\end{tabular}

\section{Palavras-chave:}

Sensitividade da Paisagem; Conectividade da Paisagem; Modelo e Evolução de Transmissão.

\section{Keywords:}

Landscape Sensitivity; Landscape Connectivity; Transmission Evolution Model.

\begin{abstract}
Resumo:
O presente trabalho visou analisar a evolução da conectividade da paisagem na bacia do riacho do Saco, semiárido pernambucano. As modificações naturais e/ou antrópicas podem gerar mudanças processuais/estruturais no sistema fluvial, sendo necessário analisar as alterações do comportamento da conectividade. Para tal, foram detalhados o comportamento do escoamento superficial e da conectividade da paisagem e de Área de Captação Efetiva; além da sensitividade da paisagem o que auxiliou a elaboração de cenários de mudança coerentes. A bacia apresenta forte desconectividade, com os patamares elevados apresentando maiores volumes de escoamento, devido a maiores taxas de precipitação e de remoção da vegetação. Os dois cenários de mudança demonstram aumento do escoamento superficial, devido a diminuição da vegetação, contudo dependendo da área modificada gera efeitos diferentes na conectividade, com aumento das incisões verticais ou assoreamento/preenchimento dos canais.
\end{abstract}

\begin{abstract}
:
This paper had a goal analyse the landscape connectivity evolution on the Saco Creek watershed, Brazilian drylands. The natural/anthropogenic changes can generate processual/structural modifications in the fluvial system, it makes necessary to analyse the connectivity behaviour fluctuations. The local runoff behaviour was detailed, as well as the landscape connectivity and the effective catchment area. The landscape sensitivity aided the creation of coherent scenarios of environmental changes. The watershed showed strong disconnectivity with
\end{abstract}


the uplands showing the highest values to average runoff, due to the high precipitation index and the natural vegetation removal. The environmental changes scenarios showed an increase of runoff due to vegetation decrease. Nevertheless, depending on the position of the modified area it can generate different effects on the connectivity, like as intensification on vertical incision or valley/channel filling.

\section{Introdução}

O gerenciamento dos recursos hídricos no semiárido brasileiro apresenta deficiências evidenciadas nos recorrentes períodos de colapso hídrico no abastecimento das comunidades (CORRÊA, TAVARES, et al., 2019). Bem como nos momentos de eventos de precipitação extrema, os quais geram enchentes nas áreas urbanas e rompimentos generalizados de barragens (SOUZA e CORRÊA, 2012b), problemas recorrentes em várias áreas do semiárido nordestino. Esses rompimentos são remobilizar altos volumes de sedimento e causar forte erosão a jusante (COLLISCHONN e TUCCI, 1997). Além da baixa qualidade técnica das barragens, vida útil dos reservatórios é limitada pela alta taxa de produção de sedimentos, gerada pela peculiaridade do sistema climático e ambiental e os padrões de uso da terra.

O entendimento da dinâmica hidrológica e sedimentológica nos canais semiáridos é essencial para a gestão dos recursos hídricos. Ao contrário das análises tradicionais, onde a transmissão de matéria é colocada como livre de impedimentos, há exemplos onde os impedimentos de transmissão nos sistemas fluviais de terras secas (árido, semiárido e subúmido) diminuem a oferta real de água nos reservatórios em até $60 \%$ (SOUZA, 2011; SOUZA e CORRÊA, 2012a). Representando, assim, um agravamento para o problema de déficit hídrico e forte variabilidade interanual, favorecendo, desse modo, problemas na gestão e recorrentes perdas econômicas e racionamentos/interrupções de abastecimento para as populações.

Assim, nota-se a necessidade do estudo da conectividade da paisagem que indica a capacidade de transmissão de água e sedimento entre os compartimentos da paisagem. Desse modo, pode-se identificar os elementos de conectantes e/ou desconectantes (BRIERLEY, FRYIRS e JAIN, 2006; COSSART e FRESSARD, 2017; WOHL, BRIERLEY, et al., 2018). Ressalta-se que a conectividade controla a evolução dos ambientes fluviais (canais e planícies de inundação), as dinâmicas de formação e destruição de paisagens e as potencialidades de recuperação. A análise da conectividade possibilita a construção de modelos espaciais e temporais sobre afetam a natureza e as taxas de velocidade de respostas a mudanças ambientais, influenciando a capacidade de recuperação dos sistemas ambientais após perturbações (BRIERLEY e FRYIRS, 2005; POEPPL, KEESSTRA e MAROULIS, 2017; HECKMANN, CAVALLI, et al., 2018).

Ao mesmo tempo é necessário avaliar as possibilidades de evolução da dinâmica fluvial e da conectividade da paisagem. Desse modo, é necessário compreender como os processos do sistema fluvial semiárido se comportariam após mudanças nos inputs do sistema, como também em mudanças em suas próprias características, mudanças tanto antrópicas quanto naturais. A partir da compreensão das relações entre os elementos do sistema seria possível avaliar a probabilidade de uma força de distúrbio produzir respostas sensíveis, reconhecíveis, sustentáveis, contudo complexas (BRUNSDEN e THORNES, 1979; BRUNSDEN, 1996; BRUNSDEN, 2001), possibilitando identificar os processos de retroalimentação, fundamental para a construção de cenários futuros coerentes com a dinâmica ambiental.

Assim, a presente pesquisa buscou analisar conectividade de água e sedimentos na bacia do riacho do Saco, localizada no semiárido de Pernambuco, e a partir dessa análise foram gerados cenários futuros para os processos de transmissão na área, baseados em diversos cenários de arranjos ambientais.

\section{Matérias e métodos}

A bacia do riacho do Saco, apresenta uma área de $142,5 \mathrm{~km}^{2}$, fazendo parte da bacia do Rio São Francisco, sendo afluente do rio Pajeú. Seu território concentra-se nos municípios de Serra Talhada e Triunfo, sertão pernambucano (figura 1), sendo componente da bacia do rio São Francisco.

Com topografia complexa e amplitude altimétrica de 700 metros, tem como principal unidade geomorfológica a Serra da Baixa Verde, intrusão sienítica parte do Planalto da Borborema (CORRÊA, TAVARES, et al., 2019; CORREA, TAVRES, et al., 2010). Dessa forma, as partes altas $(700 \mathrm{~m}$ até $1100 \mathrm{~m})$ da bacia fazem parte do Planalto da Borborema, apresentando menor temperatura média $\left(21^{\circ} \mathrm{C}\right)$ e maior precipitação anual média $(1230 \mathrm{~mm} / \mathrm{ano})$. Enquanto que os trechos mais baixos (400m até $700 \mathrm{~m}$ ) 
fazem parte da Depressão Sertaneja apresentando maior temperatura média $\left(23,8^{\circ}\right)$ e menor precipitação $(639 \mathrm{~mm} /$ ano). Essas diferenças geram quatro paisagens distintas (SOUZA, et al, 2016), apresentando distinções geomorfológicas claras: áreas subúmidas na unidade de Cabeceiras - acima de 900 metros; áreas de transição entre subúmido e semiárido nas unidades de Zona Inundável - entre 800 e 900 metros em declividades entre $0 \%$ e $3 \%$ e sazonalmente alagadas - e Escarpa de Falha - entre 600 e 800 metros com declividades acima de $45 \%$; e áreas semiáridas na unidade Pedimento - abaixo de 600 metros com presença de alguns inselbergs isolados (figura 02).

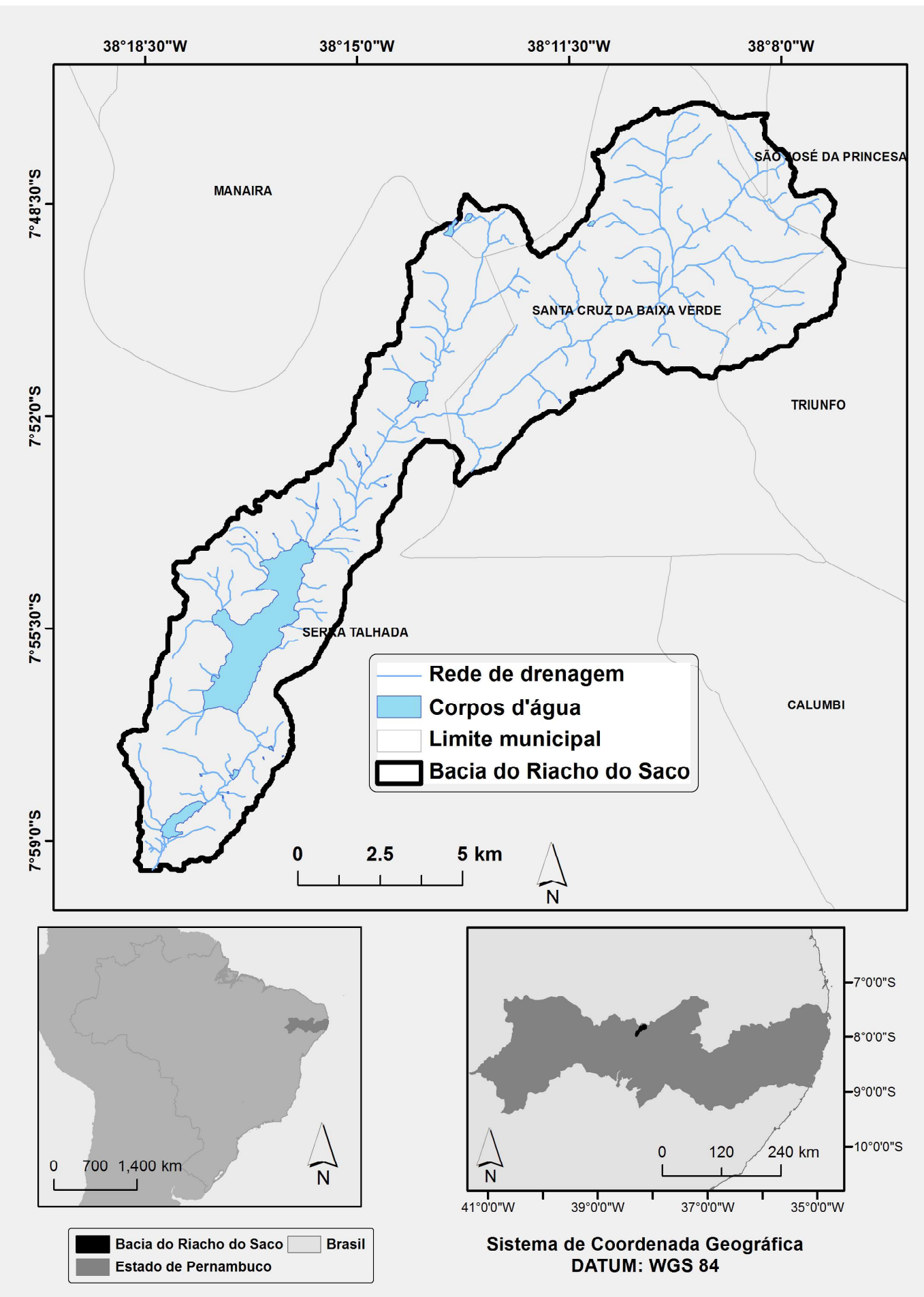

Figura 1 - Mapa de Localização 


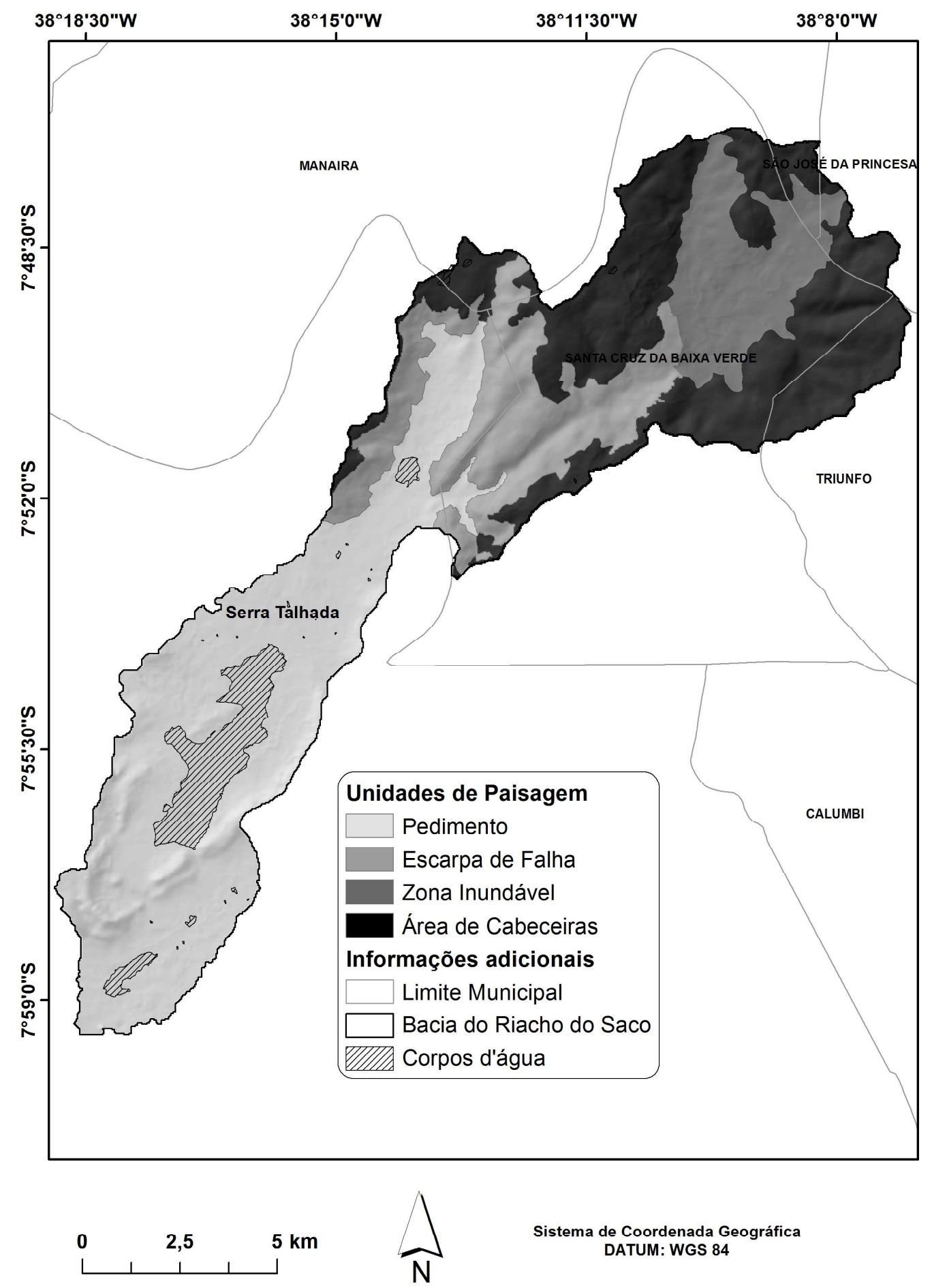

Figura 2 - Mapa de Unidades de Paisagem

A metodologia foi aplicada para avaliar a resposta conectividade a modificações naturais e/ou antrópicas no sistema, podendo gerar mudanças processuais e/ou estruturais na bacia. Desse modo, a metodologia foi dividida em três momentos:

a) avaliação do comportamento hidrológico, visando iden- tificar a magnitude e frequência dos eventos hidrológicos; b) análise da conectividade da paisagem, visando identificar o comportamento de transmissão atual de sedimentos na bacia; c) construção de cenários futuros a partir de possíveis modificações ambientais e a resposta do comportamento da conectividade para esses cenários. 
O comportamento hidrológico foi avaliado a partir do Balanço Hídrico Sequencial Diário, no qual o Excedente Hídrico Diário representaria o volume $(\mathrm{mm})$ de escoamento superficial diário, por meio do uso dos dados de precipitação diária, temperatura mensal média, e capacidade de armazenamento do solo (CHIEW, WHETTON, et al., 1995; KARNIELE e ASHER, 1993). A capacidade de campo foi definida pela porosidade do solo e a profundidade da zona radicular do solo (PAN, POTTER, et al., 2013). Os solos foram separados em três classes de porosidade média: solos argilosos com $2,0 \mathrm{~mm} / \mathrm{cm}$; solos de textura média com $1,4 \mathrm{~mm} / \mathrm{cm}$ e solos com textura arenosa com $0,6 \mathrm{~mm} / \mathrm{cm}$ (DOORENBOS e KASSAM, 1994). Já as profundidades médias para as zonas radiculares foram obtidas a partir da adaptação das profundidades médias para culturas e formações vegetais (ALFONSI, PEDRO JR., et al., 1990). Desse modo, para cada arranjo solo/cobertura foi definido capacidades de campo específica. Os dados pedológicos foram obtidos a partir do mapeamento detalhado de solos da bacia (SOUZA, 2013), e os dados de cobertura a partir da atualização do mapa de uso e cobertura da área (SOUZA, 2011). A atualização do mapa de uso e cobertura foi realizada a partir de classificação supervisionada de imagens QUICKBIRD, além de dados de campo.

Ao mesmo tempo devido à forte variação dos volumes de chuva na bacia, como colocado anteriormente, o balanço hídrico foi realizado a partir de zonas homogêneas de precipitação/capacidade de campo. Foram utilizadas quatro zonas de precipitação (SOUZA, ALMEIDA e CORREIA, 2015) separadas a partir de faixas altimétricas $(409 \mathrm{~m}-500 \mathrm{~m} ; 501 \mathrm{~m}-700 \mathrm{~m}, 701 \mathrm{~m}-900 \mathrm{~m}$ e $901 \mathrm{~m}-1118 \mathrm{~m})$. Cada qual representada por séries de dados de precipitação e evapotranspiração potencial, para o período 2006-2012, obtidas a partir de 4 PCDs meteorológicas geridas pela Agência Pernambucana de Águas e Clima.

O último passo da avaliação hidrológica foi a classificação da magnitude e frequência dos eventos de escoamento, classificando-os como magnitude baixa, moderada ou alta. A metodologia utilizada para a classificação da magnitude dos eventos foi adaptada da análise da média das precipitações máximas anuais (BEGUERIA e SERRANO, 2006; PRUDHOMME e REED, 1999), dentro da proposta de conectividade da paisagem (SOUZA, CORREA e BRIERLEY, 2016).
Essa proposta não utiliza um valor fixo visando uma melhor adequação a análise de arranjos ambientais diferentes. Bem como, se baseia na ideia de conectividade no qual os eventos de alta magnitude seriam eventos esporádicos capazes de gerar processos de modificação morfológica enquanto os eventos de magnitude moderada seriam os "eventos máximos anuais" não anômalos, não gerando a necessidade de modificação morfológica. Desse modo, tendo como base a média histórica dos eventos de escoamento diário máximo anual, a partir do qual os eventos de alta magnitude são os eventos que superam os valores médios mais o desvio padrão; os eventos de magnitude moderada entre o intervalo da média mais ou menos um desvio padrão; e os eventos de baixa magnitude seriam aqueles abaixo do valor definido pela média menos um desvio padrão.

Contudo, devido aos diferentes arranjos ambientais da bacia (solo/uso/clima) há diferentes quadros de magnitude aumentando a complexidade dessa análise. Desse modo, visando simplificar a análise, escolheu-se utilizar a média das periodicidades das magnitudes obtidas para cada zona homogênea, sendo desse modo um valor representativo para a bacia.

A análise da conectividade da paisagem focou a identificação da área de captação efetiva para cada magnitude de evento hidrológico. Ela consistiu em identificar os elementos que influenciam na transmissão de energia, tanto impedindo ou diminuindo o fluxo quanto incrementando o mesmo (FRYIRS, BRIERLEY, et al., 2007b).

Para identificar a área de captação efetiva da bacia foi necessário analisar como se comporta o transporte na bacia, diante dos vários impedimentos existentes; atualizando o levantamento realizado por Souza, Corrêa e Brierley (2016); e sob a influência de diferentes tipos de eventos chuvosos (FRYIRS, BRIERLEY, et al., 2007a; FRYIRS, BRIERLEY, et al., 2007b). As etapas da análise foram: separação das sub-bacias de cada afluente dos canais principais; identificação, classificação e mapeamento dos impedimentos de transporte de cada sub-bacia; a energia para o transporte de sedimentos a partir do gradiente nos trechos de confluência dos afluentes com o canal principal; além do comportamento da precipitação identificando os níveis de magnitude dos eventos (SOUZA, CORRÊA e BRIERLEY, 2016). Foram identificados e mapeados elementos naturais ou antrópicos que alteram a transmissão de sedimento nos 
canais, nas encostas e na interação encosta-canal; tais como barragens e planícies de inundação. $\mathrm{O}$ gradiente dos afluentes, em especial na proximidade de suas confluências é um indicador da energia disponível para o transporte, podendo atuar como elemento conectando, no caso de alto gradiente, ou elemento desconectante, no caso de baixo gradiente (FRYIRS, BRIERLEY, et al., 2007b).

Por fim, após a análise da situação atual do comportamento hidrológico da bacia e da conectividade da paisagem, foram gerados cenários de mudanças ambientais coerentes com a evolução paisagística e socioeconômica da área. Assim, esses cenários apresentam mudanças no uso e cobertura da terra visando identificar as variações na dinâmica superficial (ANDRADE, RODRIGUES, et al., 2018; CALSAMIGLIA, GARCÍA-COMENDADOR, et al., 2018). Ao mesmo tempo, a partir da análise da sensitividade da paisagem da bacia (SOUZA e CORRÊA, 2015) foi possível avaliar quais trechos fluviais e áreas das encostas são mais passíveis de apresentar modificações morfológicas, e desse modo foi possível criar cenários que abarquem essas alterações processuais e morfológicas.

Todos os procedimentos das análises do escoamento superficial, da conectividade da paisagem e da área de captação efetiva foram realizados para cada um dos cenários. Para tal, foram alteradas, para o processamento dos dados, as informações de uso e cobertura e/ou do comportamento de conectividade da estrutura fluvial.

Para cada um dos cenários foi analisado o volume escoado total da bacia, a distribuição do escoamento, a conectividade da bacia e as variações localizadas de escoamento e conectividade. Foram utilizados os dados climáticos do período 2006-2012, visto que esses dados, com a presença de anos chuvosos, secos e normais. Desse modo, foi possível identificar as possíveis modificações do comportamento ambiental da bacia, bem como especializar as respostas e adaptações a essas mudanças.

\section{Resultados e discussões}

Baseado nos dados de precipitação, uso e cobertura (figura 3-A) e solos (figura 3-B foram identificadas 24 zonas homogêneas de precipitação/capacidade de campo (figura 3-C). As áreas com baixa capacidade de campo estão diretamente relacionadas com os aflora- mentos rochosos, além de áreas com solos rasos e uso agrícola misto. Por outro lado, as áreas de maior capacidade de campo estão relacionadas a solos profundos com bom desenvolvimento e vegetação mais densa com maior desenvolvimento radicular. Baseado nas zonas homogêneas foi realizado o balanço hídrico possibilitando, entre outros resultados, a análise e espacialização do escoamento superficial da bacia (figura 3-D).

Observa-se que os maiores volumes de escoamento predominam nas altitudes mais elevadas, resultado direto não só do maior volume de precipitação nessas áreas, mas também da alta porcentagem de remoção da vegetação nativa e do uso agrícola. Desse modo a Unidade de Paisagem de Cabeceiras de Drenagem apesar de representar apenas $25,6 \%$ da área da bacia é responsável por mais de $37 \%$ do volume de precipitação captado pela bacia, alcançando $46,31 \%$ do volume escoado em toda a bacia, sendo assim a principal fonte de captação de água para a rede de drenagem da bacia. É necessário lembrar altas taxas de escoamento geram a rápida remoção da água na bacia, o que é um problema para uma região com déficit hídrico, bem como a potencialização dos processos erosivos. Deste modo, torna-se claro a necessidade do aumento dos níveis de infiltração para que a água predominantemente seja transmitida como fluxo de base e não como escoamento superficial, prolongando o tempo de permanência na paisagem.

Por fim, a periodicidade média de eventos de escoamento de magnitude moderada foi de 0,23 ano e para eventos de magnitude alta foi de 3,82 anos. Por utilizar valores relacionados com o arranjo ambiental de cada área o método é adequado para a identificação dos eventos causadores de distúrbios para cada estrutura ambiental, em especial para os ambientes fluviais.

Para a análise da conectividade da paisagem, foram identificados vários tipos de impedimentos (figura 4-A): vales preenchidos conservados, vales parcialmente preenchidos, barramento de canais, canais tributários aprisionados, planícies de inundação e estradas. Os vales preenchidos são os trechos aluviais o preenchimento de sedimentos limita completamente a formação de canal escavado onde há o preenchimento sedimentar do vale, no caso dos trechos de vales preenchidos conservados, ou a presença de canais descontínuos, para os trechos de vale parcialmente preenchidos. As áreas urbanas foram consideradas por modificarem de forma diferenciada a transmissão dos fluxos. 


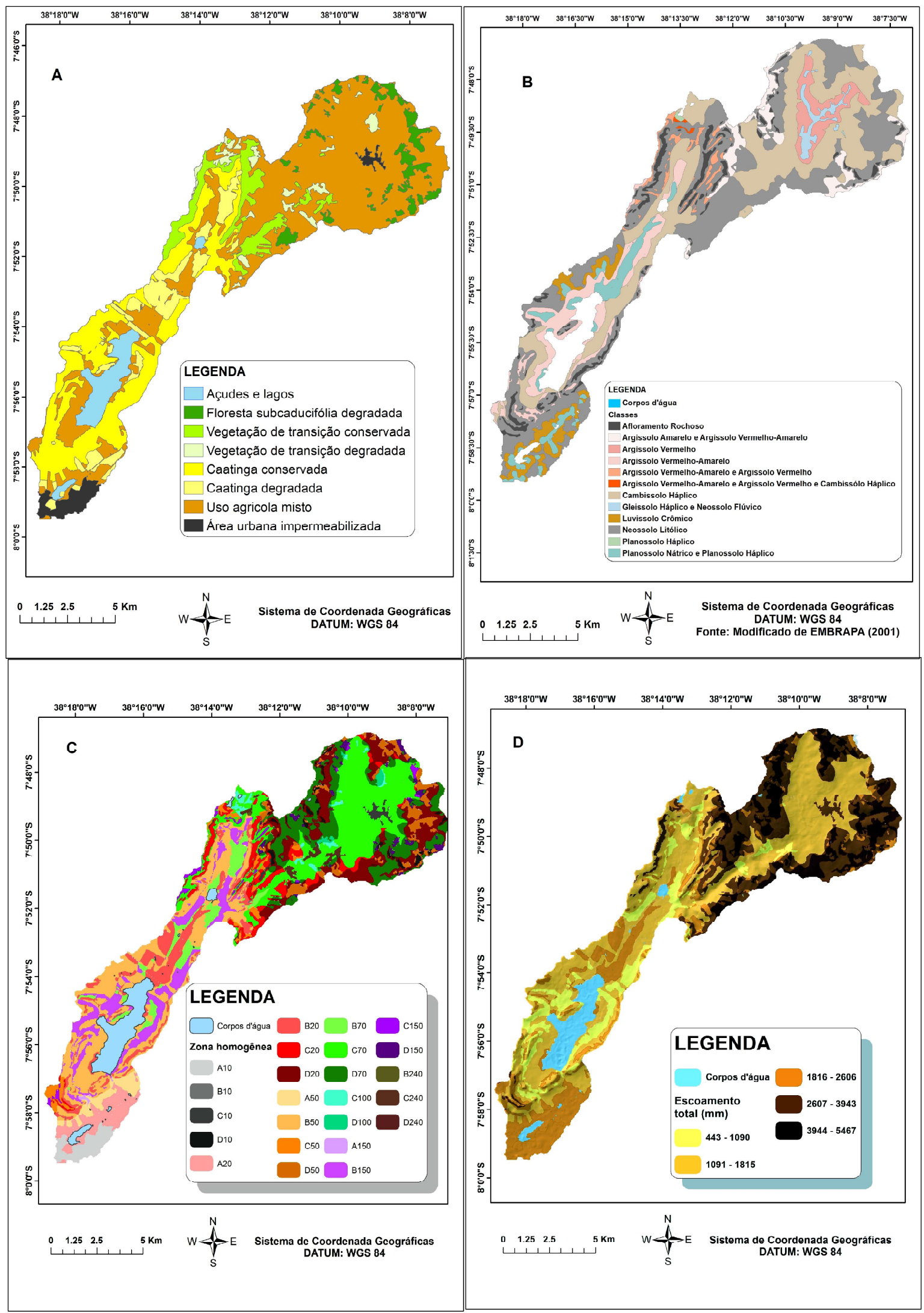

Figura 3 - A - Mapa de cobertura da terra (atualizado de Souza, 2011). B - Mapa detalhado das classes de solo (SOUZA, 2013). C - Zonas homogêneas de faixa de precipitação (letra de A, menor altitude e mais seco, até D, maior altitude e mais úmido) e capacidade de campo em mm (identificado pelos números). D - Total escoado entre os anos de 2006 e 2012 para a bacia do riacho do Saco. 


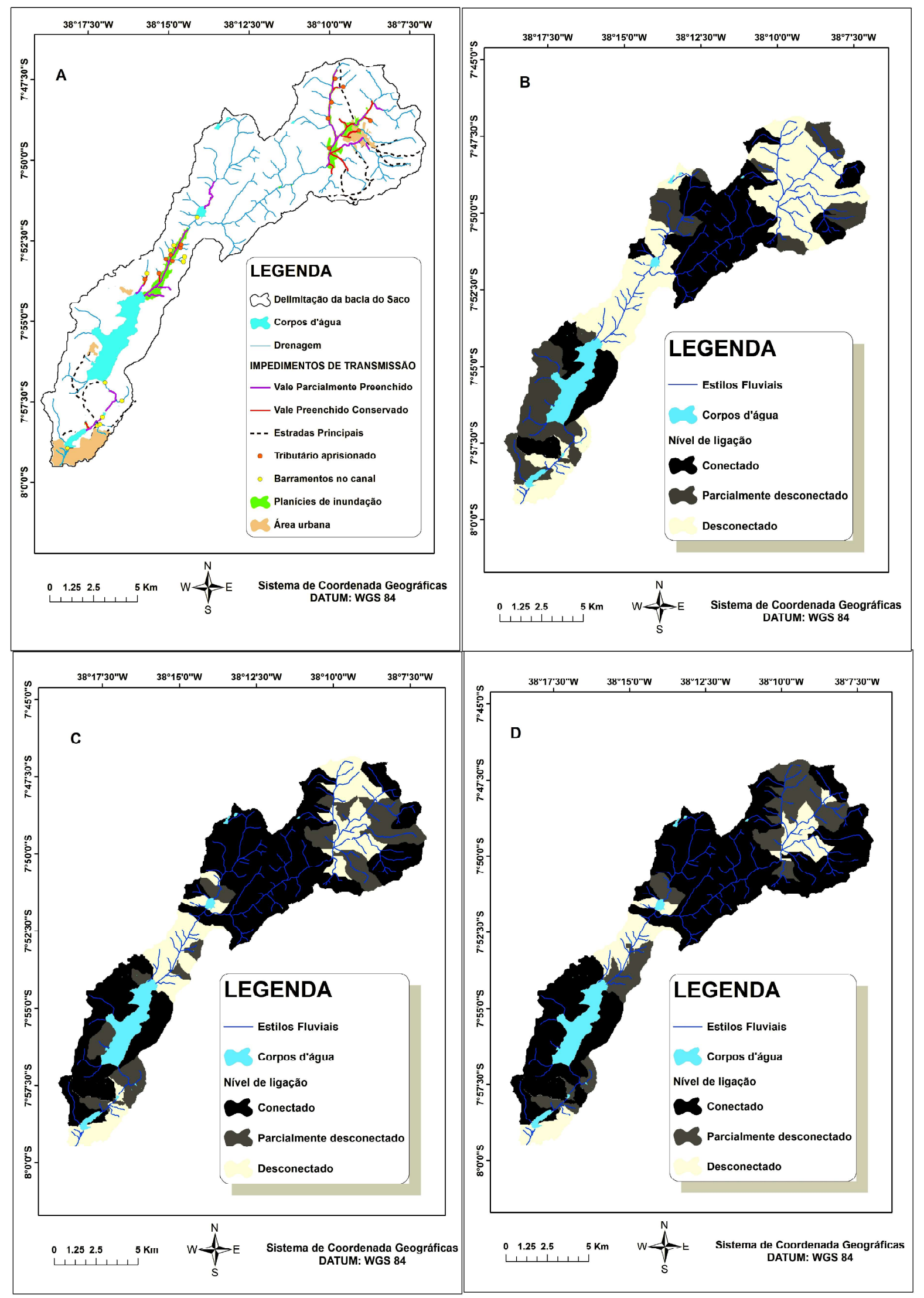

Figura 4 - A-Elementos desconectantes. B-Eventos de magnitude baixa. C-Eventos de magnitude moderada. D-Eventos de magnitude alta (adaptado e atualizado de SOUZA, CORREA e BRIERLEY, 2016) 
A análise da área de captação efetiva na escala da bacia (figura 4-B, C e D) apresenta duas principais modificações em relação aos diferentes cenários. Quando se compara os eventos de baixa magnitude com os eventos de magnitude moderada observa-se um aumento de $36,4 \%$ para $60,0 \%$ nas áreas conectadas. Esse aumento está diretamente relacionado a conexão das sub-bacias que apresentam baixa declividade nos exutórios, as quais apresentam-se desconectados durante os eventos de baixa magnitude devido à falta de competência do fluxo para transportar os sedimentos.

Contudo, ao analisar as mudanças entre os cenários de magnitude moderada e alta não há mudanças significavas nas áreas conectadas, visto que as desconexões estão relacionadas por barramentos de canais e por vales preenchidos (conservados, dissecados e de tributários aprisionados). Nesses trechos apenas alguns açudes mais rudimentares são superados nos eventos de magnitude alta, enquanto que os outros elementos permanecem desconectando as sub-bacias, ao menos parcialmente; mantendo, assim, áreas não conectadas mesmo em eventos de alta magnitude.

As diferentes magnitudes dos eventos conjuntamente com as relações de transmissão, também, têm papel de fundamental importância no comportamento da atividade geomórfica, como por exemplo, durante os eventos de magnitude moderada/alta, os preenchimentos de vale, podem ser retrabalhados através da formação de incisões verticais, contínuas ou descontínuas, bem como as planícies de inundação podem ser retrabalhadas lateralmente. Já outras modificações podem estar relacionadas com o uso e ocupação, tal como, a construção de barramentos que ao diminuir a relação de transmissão entre os compartimentos, acentua o processo de preenchimento de vale, podendo suprimir a incisão do canal, gerando trechos de preenchimento sedimentar.

Como uma primeira tentativa de entender possíveis modificações futuras na bacia foram elaborados dois cenários de mudanças ambientais para avaliar o impacto de mudanças no escoamento superficial e na capacidade de transmissão na bacia. Tentou-se construir cenários dentro de comportamentos coerentes para modificações nos arranjos socioambientais. Foram pensados dois cenários com mudanças de uso e cobertura da terra e a partir da análise da sensitividade da paisagem também foi inserido mudanças morfológicas/processuais nas encostas e canais que afetam o comportamento da conectividade (tabela 1). Para cada um dos cenários foi analisado o volume escoado total da bacia, a distribuição do escoamento, a conectividade da bacia e as variações localizadas de escoamento e conectividade.

Tabela 1: Cenários de mudança ambientais para a bacia do Riacho do Saco

\begin{tabular}{|c|c|c|c|c|}
\hline & $\begin{array}{l}\text { Variação no } \\
\text { Volume escoado }\end{array}$ & $\begin{array}{l}\text { Variação no Grau } \\
\text { de conectividade }\end{array}$ & Área afetada & Comportamento das mudanças \\
\hline $\begin{array}{c}\text { Cenário 1: } \\
\text { Degradação da } \\
\text { vegetação de } \\
\text { caatinga/transição } \\
\text { e aumento na } \\
\text { incisão vertical }\end{array}$ & $+6,7 \%$ & $+2,5 \%$ & $27,96 \%$ & $\begin{array}{c}\text { Diminuição da capacidade de campo } \\
\text { máxima das áreas afetadas. Aumento } \\
\text { do escoamento e da energia de } \\
\text { transmissão. } \\
\text { Aumento da intensidade da incisão } \\
\text { vertical nos vales preenchidos. Criação } \\
\text { de canais contínuos. Aumento da } \\
\text { conectividade entre áreas isoladas }\end{array}$ \\
\hline $\begin{array}{l}\text { Cenário 2: } \\
\text { Aumento do } \\
\text { cultivo na área } \\
\text { agriculturável } \\
\text { e intensificação } \\
\text { dos processos de } \\
\text { voçorocamentos }\end{array}$ & $+2,6 \%$ & $-5,4 \%$ & $7,39 \%$ & $\begin{array}{l}\text { Diminuição do CAD máximo das } \\
\text { áreas afetadas. Aumento da energia de } \\
\text { transmissão. } \\
\text { Aumento na energia para erosão das } \\
\text { encostas. Intensificação/reativação de } \\
\text { processos de voçorocamento nas áreas } \\
\text { de alta sensitividade. } \\
\text { Assoreamento dos canais a jusante }\end{array}$ \\
\hline
\end{tabular}


O primeiro cenário (figura 5) abarca a possibilidade de degradação das áreas de vegetação conservada, mudando a classe para áreas de vegetação degradada. Tal cenário é provável a partir de vários mecanismos como por exemplo a remoção parcial da vegetação para produção de carvão, o que é comum especialmente du-
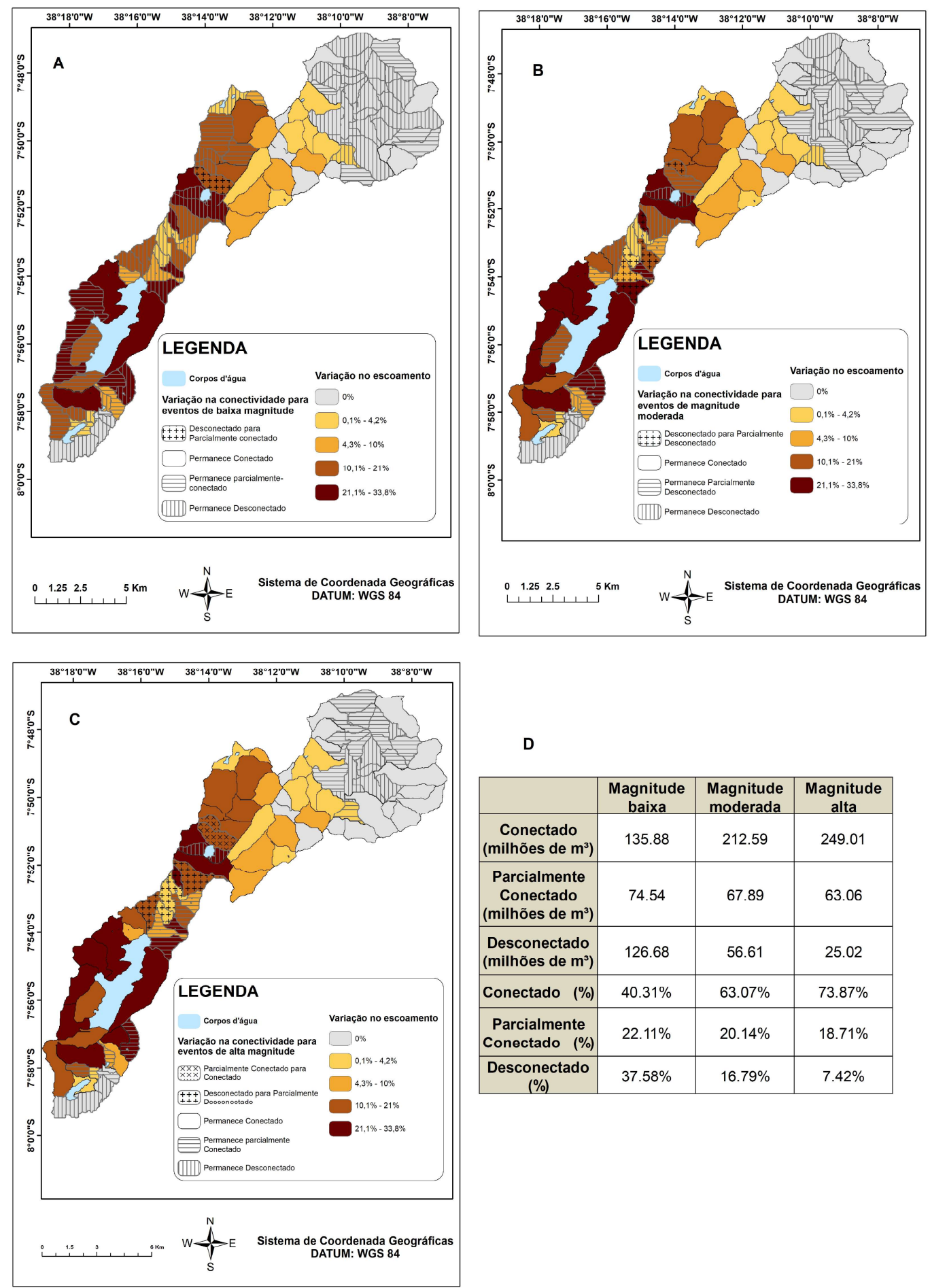

D

\begin{tabular}{|c|c|c|c|}
\hline & $\begin{array}{c}\text { Magnitude } \\
\text { baixa }\end{array}$ & $\begin{array}{l}\text { Magnitude } \\
\text { moderada }\end{array}$ & $\begin{array}{l}\text { Magnitude } \\
\text { alta }\end{array}$ \\
\hline $\begin{array}{c}\text { Conectado } \\
\text { (milhões de } \mathrm{m}^{3} \text { ) }\end{array}$ & 135.88 & 212.59 & 249.01 \\
\hline \begin{tabular}{|c|} 
Parcialmente \\
Conectado \\
$\left(\right.$ milhões de m $^{3}$ )
\end{tabular} & 74.54 & 6789 & 63.06 \\
\hline $\begin{array}{c}\begin{array}{c}\text { Desconectado } \\
\left(\text { mllhoes de } \mathrm{m}^{\circ}\right)\end{array} \\
\end{array}$ & 126.68 & 56.61 & 25.02 \\
\hline Conectado (\%) & $40.31 \%$ & $63.07 \%$ & $73.87 \%$ \\
\hline $\begin{array}{l}\text { Parcialmente } \\
\text { Conectado (\%) }\end{array}$ & $22.11 \%$ & $20.14 \%$ & $18.71 \%$ \\
\hline $\begin{array}{c}\text { Desconectado } \\
(\%)\end{array}$ & $37.58 \%$ & $16.79 \%$ & $7.42 \%$ \\
\hline
\end{tabular}

Figura 5 - Cenário de degradação da vegetação de caatinga/transição e aumento na incisão vertical; relação entre a Área de Captação Efetiva e o volume médio escoado por $\mathrm{Km}^{2}$ para cada magnitude de evento. A - Evento de baixa magnitude; B - evento de magnitude moderada; $C$ - evento de alta magnitude; D-Relação escoamento e conectividade. 
Resultando em valores menores de CAD máximo, e consequentemente maior volume escoado e maior potencial erosivo. Ao analisar a sensitividade das regiões diretamente afetadas (SOUZA e CORRÊA, 2015), observa-se que as áreas de encosta afetadas não apresentam alta sensitividade, devido a presença de solos rasos, não gerando erosão linear nas encostas, mantendo a predominância do fluxo hortoniano. Contudo, uma parte dessas áreas estão associadas a trechos de preenchimento de vale preenchido - conservados, dissecados e de tributários aprisionados (figura 4-A) - trechos que apresentam alta sensitividade a mudanças. Desse modo, o aumento do escoamento geraria um aumento na energia do fluxo nos vales fluviais induzindo uma maior incisão nos trechos a jusante das áreas modificadas (BRIERLEY e FRYIRS, 1999), gerando canais contínuos. Esse processo altera e remove de alguns desses elementos desconectantes, e consequentemente aumentando a conectividade dessas áreas. Assim, esse cenário além de apresentar modificações no escoamento, também apresenta modificações na conectividade.

Avaliando o contexto da bacia como um todo nesse cenário a mudança atingiu $27,96 \%$ da área da bacia, provocando um acréscimo de $6,7 \%$ do volume escoado (figura 5). Ao mesmo tempo, houve um acréscimo para os eventos de alta magnitude nas áreas conectadas, alcançando $73,87 \%$, além de um decréscimo das áreas desconectadas de $11,11 \%$ para $7,42 \%$. Contudo a análise da espacialização das mudanças aponta que as mudanças se concentraram na área central da bacia, nas unidades de Pedimento e Escarpa de Falha (figura 5). Analisando apenas essa área o aumento do volume escoado chegou a $15,4 \%$, no cenário com a degradação da vegetação. $O$ aumento é ainda mais drástico ao se analisar na escala de sub-bacia, chegando a um aumento de escoamento superior a $30 \%$ em algumas delas.

Ao mesmo tempo observa-se que as mudanças se concentram em sub-bacias a montante de dois açudes, inclusive o Açude do Saco (o maior da bacia), de modo que as alterações podem impactar diretamente esses reservatórios. Nessa perspectiva a análise da modificação da conectividade, tendo como base a análise da sensitividade da paisagem, demonstra a possibilidade que o aumento do escoamento superficial local gerará mais energia para o fluxo fluvial. Assim, o fluxo poderá remover alguns impedimentos deposicionais aumentando o processo de incisão vertical, modificando parte dos trechos de preenchimento de vale e sem a presença de canal contínuo para trechos com planícies de inundação e canal contínuo, predominando relações parcialmente conectadas (devido a presença das planícies de inundação (figura 5-C).

Esse aumento de conectividade altera diretamente a configuração geral da conectividade entre os grandes compartimentos da bacia. A presente bacia apresenta-se com forte desconexão controlada pela presença de barragens, sem a dinâmica para liberação de água, e de longos trechos de vale preenchido de sedimentos sem canal contínuo (SOUZA, CORREAA e BRIERLEY, 2016), trechos de deposição relacionados ao baixo gradiente dos canais, podendo ter influência de barramentos ou não. Ressalta-se que esse comportamento e características são comuns para as áreas secas, visto que a falta de fluxo de água contínuo não favorece a incisão vertical e formação de canais bem definidos. Porém, a modificação estrutural pensada para esse cenário afeta a conectividade local montante do açude do Saco, no qual predominava trechos de preenchimento de vale, e atuava retendo grande parte do sedimento gerado a montante, especialmente pela Unidade de Escarpa de Falha. Desse modo, a mudança conecta essas duas unidades, e consequentemente os sedimentos produzidos na região da Escarpa de Falha alcançara mais facilmente o açude.

O segundo cenário (figura 6) foi criado baseado na ideia de expansão da área de uso agrícola (figura 3-A). Devido a dinâmica socioambiental da bacia as áreas prováveis para a expansão foram localizadas nas regiões mais altas da bacia, no topo da Unidade de Escarpa de Falha, e nas unidades de Zona Inundável e Áreas de cabeceira. Tal cenário é provável visto a possibilidade do aumento da pressão antrópica, aumento da população, e expansão de capital aplicado na agricultura. Baseado nisto, a base espacial de uso e cobertura foi modificada, na qual às áreas de vegetação de transição degradada e as áreas de floresta subcaducifólia degradadas foram substituídas por áreas de uso agrícola misto.

Novamente, a modificação irá gerar uma diminuição localizada no CAD máximo, diminuindo os valores de infiltração e aumentando o escoamento, consequentemente o potencial erosivo. Contudo, diferente do primeiro cenário, ao analisar a sensitividade das regiões diretamente afetadas (SOUZA e CORRÊA, 2015) observa-se que as encostas apresentam alta sensitividade a mudanças. Sendo caracterizadas por encostas côncavas, morfologia que concentra o fluxo, com cobertura coluvial e presença de processos de voçorocamento atuais ou marcas de processos pretéritos. Ressalta-se 
que em alguns pontos as voçorocas apresentam-se ligadas formando redes de erosão e se comportando como linhas de drenagem (SOUZA, BARROS e CORREAA, 2016). O aumento do escoamento superficial nessas áreas possibilita a formação de novas voçorocas, bem como a reativação de antigas voçorocas, ou até a in- tensificação do processo erosivo nas já atuantes. Esses mecanismos resultaram em um aumento abrupto na oferta de sedimentos para os ambientes fluviais a jusante desses pontos, possibilitando o assoreamento dos vales que apresentem baixo gradiente, ou seja, baixa energia para evacuação dessa nova carga de sedimentos.
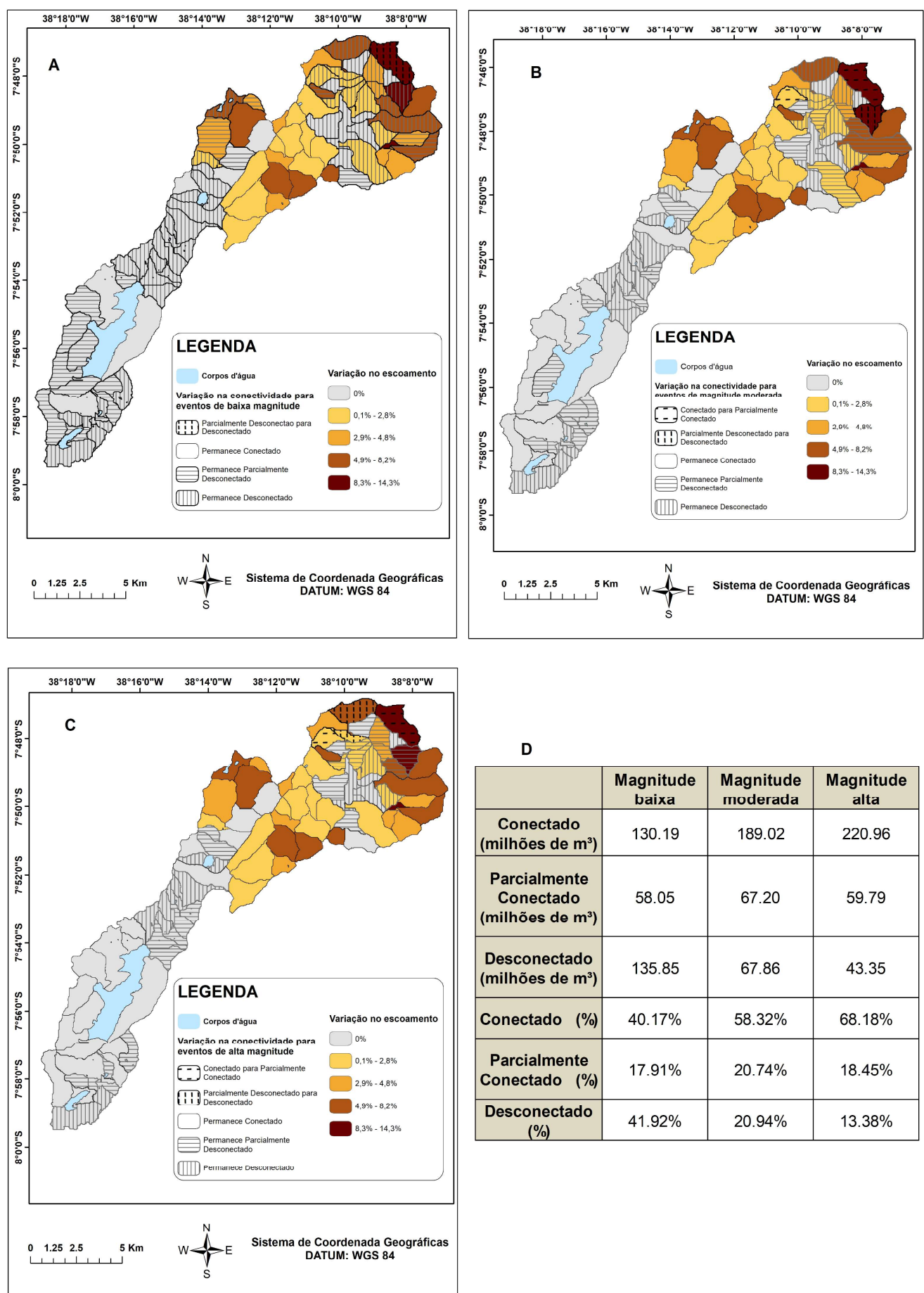

D

\begin{tabular}{|c|c|c|c|}
\hline & $\begin{array}{c}\text { Magnitude } \\
\text { baixa }\end{array}$ & $\begin{array}{l}\text { Magnitude } \\
\text { moderada }\end{array}$ & $\begin{array}{c}\text { Magnitude } \\
\text { alta }\end{array}$ \\
\hline $\begin{array}{c}\text { Conectado } \\
\text { (milhões de } \mathrm{m}^{3} \text { ) }\end{array}$ & 130.19 & 189.02 & 220.96 \\
\hline $\begin{array}{c}\text { Parcialmente } \\
\text { Conectado } \\
\text { (milhões de } \mathbf{m}^{3} \text { ) }\end{array}$ & 58.05 & 67.20 & 59.79 \\
\hline $\begin{array}{c}\text { Desconectado } \\
\left.\text { (milhões de } \mathrm{m}^{3}\right)\end{array}$ & 135.85 & 67.86 & 43.35 \\
\hline Conectado (\%) & $40.17 \%$ & $58.32 \%$ & $68.18 \%$ \\
\hline $\begin{array}{c}\text { Parcialmente } \\
\text { Conectado (\%) }\end{array}$ & $17.91 \%$ & $20.74 \%$ & $18.45 \%$ \\
\hline $\begin{array}{c}\text { Desconectado } \\
(\%)\end{array}$ & $41.92 \%$ & $20.94 \%$ & $13.38 \%$ \\
\hline
\end{tabular}

Figura 6 - Cenário de aumento da área agrícola na área agriculturável da bacia e aumento/reativação de processos de voçorocamento. Relação entre a Área de Captação Efetiva e o volume médio escoado por $\mathrm{Km}^{2}$ para cada magnitude de evento. A-Magnitude baixa. BMagnitude Moderada. C-Magnitude Alta. D-Relação escoamento e conectividade. 
Deste modo, para as sub-bacias a jusante dessas áreas que apresentaram gradientes no exutório abaixo de $2^{\circ}$ (declividade comum para vales preenchidos) foram inseridos impedimentos de preenchimento de vale, tal como tributários aprisionados, canais descontínuos e vales preenchidos.

Tais modificações afetam a conectividade desses trechos, assim, como no anterior, esse cenário apresentou modificações nos volumes escoados e na conectividade da paisagem.

Desse modo, a modificação no uso e cobertura da terra gerou uma diminuição do CAD máximo afetando $7,39 \%$ da área da bacia e aumentando o volume escoado total em 2,6\%. Sendo as modificações concentradas nas áreas com declividade média nas regiões mais altas da bacia, nas quais haveria o aumento do volume escoado, incluindo nas áreas que já representam as maiores produtoras de escoamento por $\mathrm{Km}^{2}$. Ressalta-se que apesar do aumento percentual ser baixo, quando comparado ao valor total de escoamento produzido pela bacia, localmente ao se observar na escala de sub-bacia o aumento pode chegar a cerca de $14 \%$. Tal aumento localiza-se especificamente em áreas com alta sensitividade, como já colocado, e sujeitas a processos de voçorocamento, aumentando o aporte de sedimentos aos vales a jusante dessas áreas.

Nesta perspectiva a mudança da conectividade para esse cenário concentra-se na diminuição da conectividade baseada na criação e/ou modificação de impedimentos sedimentares, do tipo de preenchimento de vale, nos vales a jusante com baixo gradiente. Gerando uma diminuição de 5,4\% na conectividade da bacia, concentrando-se nas sub-bacias que abarcam a base das áreas mais elevadas da bacia. Ressalta-se que essas sub-bacias ficam na parte superior da Unidade de Paisagem classificada como Zona Inundável, estando diretamente a montante de sub-bacias com alto índice de desconectividade, onde há o predomínio de elementos desconectantes de vale preenchido. Desse modo, haveria a expansão dessa área de preenchimento de vale, e consequentemente de inundação, podendo afetar diretamente as comunidades locais. Por fim, é importante colocar que apesar do aumento da desconectividade poder representar o aumento do risco de inundação para as comunidades locais, ele também representa um aumento das áreas de aquífero aluvial com uma maior retenção de sedimentos e água nessas localidades.
A evolução recente da dinâmica sedimentológica na bacia do Riacho do Saco tem sido dominada pela estocagem de sedimentos em lagos de açudes, em preenchimentos de vale a montante dos açudes e em trechos com vales preenchidos. Esses pontos/trechos desconectam as áreas a montante da jusante, isolando o transporte de carga de fundo, visto que apesar do grande volume de escoamento que chega a esses locais, a declividade próxima de zero gera perda de energia e a deposição do material provenientes das áreas a montante; como também é observado em diferentes arranjos ambientais (FRYIRS E BRIERLEY, 1999; PHILLIPS E SLATTERY, 2006; HARVEY, 2012). Sofrendo influências não apenas da variação natural da declividade, mas também nas modificações e flutuações dos níveis de base local, como acontece em áreas com barragens.

Esses trechos de depósito aluviais podem reter água em subsuperfície, a qual pode ser obtida a partir de poços rasos, técnica comum na região semiárida, porém esses depósitos normalmente são ignorados pela gestão de recursos hídricos predominantes. Esses aquíferos aluviais poderiam ser integrados em gestões ambientais multi-escalar (LOVE et al, 2011), sendo necessário estudos para identificação, análise e conservação dessas áreas. Contudo, para realizar essa integração é primordial o entendimento do comportamento climático e de suas respostas hidrossedimentológica.

Avaliando a relação dos tipos de eventos, o estudo indica que os eventos de magnitude moderada são o principal agente geomórfico em relação ao transporte de sedimento de fundo, semelhante ao colocado por Wolman e Miller (1960). Essa afirmação é embasada na pouca diferenciação na conectividade entre os eventos de moderada e alta conectividade, onde a diferença entre os dois é baixa, se comparado à grande variação na periodicidade dos mesmos. Por outro lado, os eventos de magnitude baixa geram transferência localizada dos sedimentos, sendo interrompidos pelos impedimentos como no caso dos vales planos, sendo o principal responsável pelo processo de preenchimento dos vales.

\section{Considerações}

Ao analisar os resultados desses dois cenários fica claro a necessidade de entender as mudanças de forma multi-escalar, visto que ao entender as mudanças dos processos superficiais de forma localizada é possível compreender quais pontos sofrerão maiores níveis de 
distúrbio. Ao mesmo tempo, o entendimento da sensitividade é primordial para a criação coerente de cenários com mudanças estruturais nas encostas, bem como nos ambientes fluviais. Observou-se que apesar do alto nível de desconectividade, mudanças localizadas podem gerar modificações não apenas locais, mas com impacto para áreas adjacentes.

Entender as possibilidades de evolução da transmissão de fluxo e de sedimento é essencial para a gestão dos recursos hídricos e planejamento de uso e ocupação da região semiárida, especialmente devido a irregularidade das chuvas e as diversas modificações e impactos antrópicos. Os resultados e considerações obtidos são representativos para diversas áreas tropicais semiáridas, incluindo o nordestino. Visto que a bacia apresenta um arranjo socioambiental típico, especialmente para áreas de transição semiárida para áreas de enclaves sub-úmidos, áreas importantes ambientalmente e economicamente. As áreas elevadas representam bolsões férteis e com um balanço hídrico mais favorável do que as áreas semiáridas; como pode ser visto na diferença de ocupação entre essas áreas, semiárida com predominância de pecuária extensiva e pastagem natural; e o sub-úmida com agricultura mista

A metodologia/modelo proposto para a análise da transmissão entre os compartimentos da paisagem, especialmente transporte de sedimento de carga de fundo, baseada na conectividade da paisagem, pode ser usada adequadamente para avaliar os fluxos e estocagem de sedimento, e secundariamente água, para áreas com falta de série de dados de informações hidrossedimentológicas. A efetividade das soluções do planejamento e da engenharia, tal como a transposição do rio São Francisco, depende do entendimento apropriado do comportamento do sistema geomorfológico e suas inter-relações hidrossedimentológicas. O presente estudo criou um método/sistemático para realizar uma análise inicial da conectividade da paisagem, do comportamento dos fluxos da região, e em especial dos impactos gerados por uma série de modificações possíveis para a área em um futuro próximo; podendo a partir da simulação de cenários embasar políticas e ações de planejamento ambiental, de recursos hídricos e de uso/ocupação.

\section{Agradecimento}

A Fundação de Amparo à Ciência e Tecnologia de PE-FACEPE, pelo financiamento da presente pesquisa.

\section{Referências Bibliográficas}

ALFONSI, R. R. et al. Métodos agrometeorológicos para controle da irrigação. Campinas: Instituto Agronômico, 1990.

ANDRADE, E. M. D. et al. Hydrological responses of a watershed to vegetation changes in a tropical semiarid region. Rev. Caatinga, v. 31, n. 1, p. $161-170,2018$.

BRIERLEY, G. J.; FRYIRS, K. A. Geomorphology and River Management: Applications of the River Styles Framework. Oxford: Blackwell Publications, 2005.

BRIERLEY, G.; FRYIRS, K. A.; JAIN, V. Landscape connectivity: the geographic basis of geomorphic applications. Area, v. 38 (2), p. 65-174, 2006.

BRUNSDEN, D. Geomorphological events and landform change. Zeitschrift für Geomorphologie, v. 40, p. 273-288, 1996.

BRUNSDEN, D. A critical assessment of the sensitivity concept in geomorpholog. Catena, v. 42, n. 2-4, p. 99-123, 2001.

BRUNSDEN, D.; THORNES, J. B. Landscape Sensitivity and Change. Transactions of the Institute of British Geographers, New Series, v. 4, n. 4, p. 463-484, 1979.

CALSAMIGLIA, A. et al. Effects of agricultural drainage systems on sediment connectivity in a small Mediterranean lowland catchment. Geomorphology, v. 318, p. 162-171, 2018.

CHIEW, F. H. S. et al. Simulation of the impacts of climatic change on runoff and soil moisture in Australian catchments. Journal of Hydrology, n. 167, p. 121-147, 1995.

COLLISCHONN, W.; TUCCI, C. E. M. Análise do rompimento hipotético da barragem de Ernestina. Revista Brasileira de Recursos Hídricos, v. 2 n.2, p. 191-206, 1997.

CORRÊA, A. A. et al. The Semi-arid Domain of the Northeast of Brazil. In: SALGADO, A. A. R.; SANTOS, L. J. C.; PAISANI, J. C. The Physical Geography of Brazil. Cham: Springer, 2019. p. 119-150.

CORREA, A. C. B. et al. Megageomorfologia e Morfoestrutura do Planalto da Borborema.. Revista do Instituto Geológico, v. $31(1 / 2)$, p. 35-52, 2010.

COSSART, É.; FRESSARD, M. Assessment of structural sediment connectivity within catchments: insights from graph theory. Earth Surf. Dynam, v. 5, p. 253-268, 2017.

DOORENBOS, J.; KASSAM, A. H. Efeito da água no rendimento das culturas. Campina Grande: UFPB, 1994. 
FRYIRS, K. A. et al. Buffers, barriers and blankets: The (dis) connectivity of catchment-scale sediment cascades. Catena, v. 70, p. 49-67, 2007a.

FRYIRS, K. A. et al. Catchment-scale (dis)connectivity in sediment flux in the upperHunter catchment, New South Wales, Australia. Geomorphology, v. 89, p. 297-316, 2007 b.

HECKMANN, T. et al. Indices of sediment connectivity: opportunities, challenges and limitations. Earth-Science Reviews, v. 187, p. 77-108, 2018.

KARNIELE, A.; ASHER, J. B. A daily runoff simulation in semi-arid watersheds based on soil water deficit calculations. Journal of Hydrology, n. 149, p. 9-25, 1993.

PAN, X. et al. Hillslope-scale probabilistic characterization of soil moisture dynamics and average water balance. Hydrological Processes, v. 27, p. 1464-1474, 2013.

POEPPL, R.; KEESSTRA, S.; MAROULIS, J. A conceptual connectivity framework for understanding geomorphic change in human-impacted fluvial systems. Geomorphology, v. 277, p. 237-250, 2017.
SOUZA, J. O. P. Sistema fluvial e açudagem no semi-árido, relação entre a conectividade da paisagem e dinâmica da precipitação, na bacia de drenagem do riacho do saco, Serra Talhada, Pernambuco. Dissertação (Mestrado) - Universidade Federal de Pernambuco. Programa de Pós-Graduação em Desenvolvimento e Meio ambiente. Recife, p. 169. 2011.

SOUZA, J. O. P.; CORRÊA, A. C. B. Estilos fluviais num ambiente semiárido, bacia do Riacho do Saco, Pernambuco. Finisterra, LI, 102, pp. 3-23, 2016.

SOUZA, J. O. P.; BARros, A. C. M.; CORRÊA, A. C. B. Conectividade e área de captação efetiva de um sistema fluvial semiárido: bacia do riacho Mulungu, Belém de São FranciscoPE. Sociedade e Natureza, v. 24, n. 2, p. 379-332, 2012a.

SOUZA, J. O. P.; CORRÊA, A. C. B. Sistema fluvial e planejamento local no semiárido. Mercator, v. 11, p. 149-168, $2012 b$.

WOHL, et al. Connectivity as an emergent property of geomorphic systems. Earth Surf. Process. Landforms, p. $1-23,2018$. 